\title{
Erratum to: Preoperative Echocardiographic-Defined Moderate-Severe Pulmonary Hypertension Predicts Prolonged Duration of Mechanical Ventilation Following Lung Transplantation for Patients with COPD
}

Jeremy P. Wrobel • Bruce R. Thompson •

Gregory I. Snell · Trevor J. Williams

Published online: 20 February 2013

(C) Springer Science+Business Media New York 2013

Erratum to: Lung (2012) 190(6):635-643

DOI 10.1007/s00408-012-9423-7

In Fig. 2 on page 638 of the original publication of this article, the overall $P$ values were misprinted for the middle and lower panels. The middle panel should read "Overall $P=0.055$ " and the lower panel should read "Overall $P=$ 0.027 ". The $P$ values were correctly printed in the text and in Table 4. The corrected version of Fig. 2 is shown here.

The online version of the original article can be found under doi:10.1007/s00408-012-9423-7.

J. P. Wrobel $(\varangle)$ · B. R. Thompson · G. I. Snell · T. J. Williams Faculty of Medicine, Monash University, 55 Commercial Road, Melbourne, VIC 3004, Australia

e-mail: jeremywrobel@gmail.com

J. P. Wrobel · B. R. Thompson · G. I. Snell - T. J. Williams Department of Allergy, Immunology and Respiratory Medicine, The Alfred Hospital, 55 Commercial Road, Melbourne,

VIC 3004, Australia 

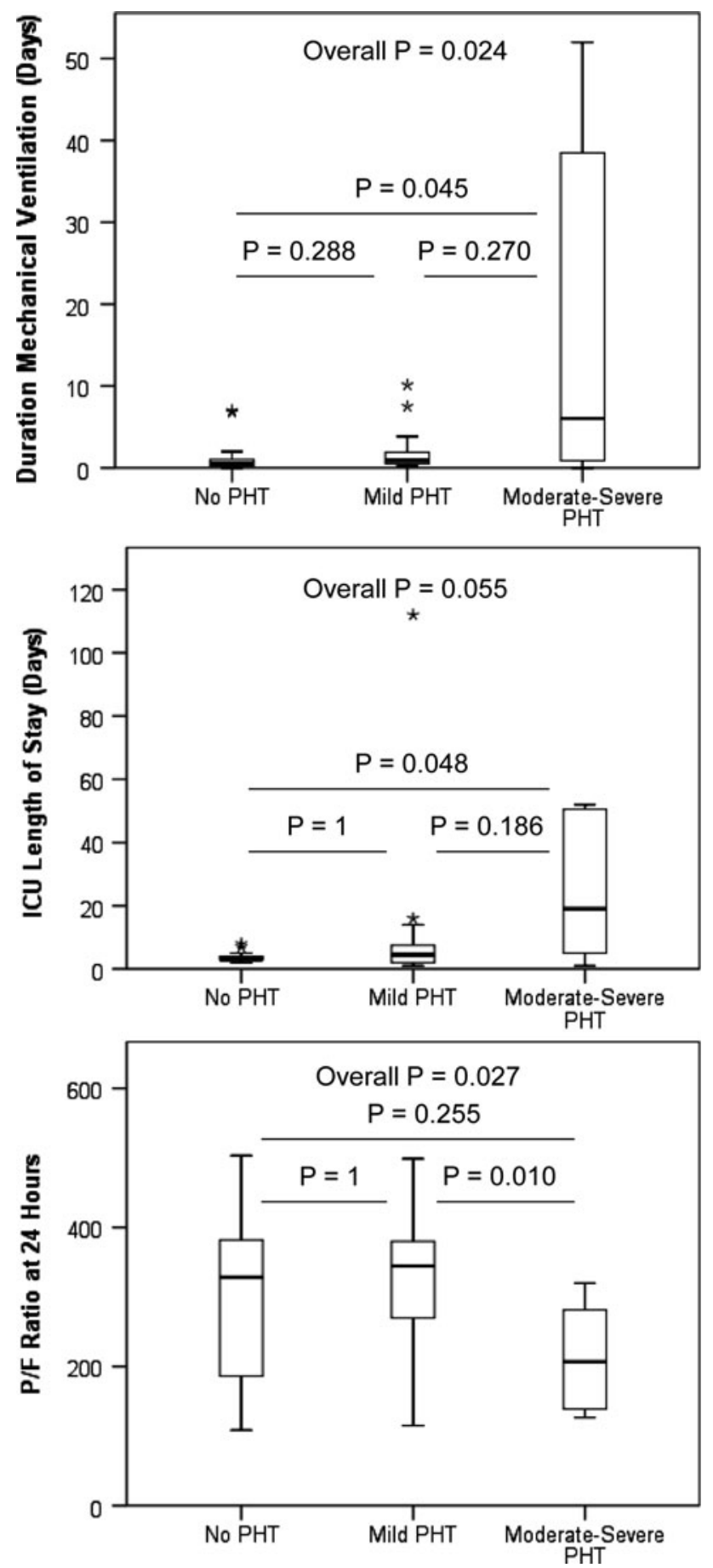

Fig. 2 Duration of mechanical ventilation (a), ICU length of stay (b), and $\mathrm{P} / \mathrm{F}$ ratio at $24 \mathrm{~h}$ (c) according to pulmonary arterial pressure group. The box plot illustrates the minimum, lower quartile, median, upper quartile, and maximum values for each group. Asterisk represents outliers. $P$ values are calculated using the Kruskal-Wallis one-way analysis of variance. Post-hoc pair wise comparisons were adjusted by a Bonferroni correction. ICU intensive care unit; $n s$ not significant; $P / F$ ratio $\mathrm{PaO}_{2} /$ fraction of inspired $\mathrm{O}_{2}$ ratio; $P H T$ pulmonary hypertension 